\title{
AVALIAÇÃO DOS IMPACTOS AMBIENTAIS NOS ESTUÁRIOS DAS REGIÕES DE CARAVELAS E MUCURI (BA-BRASIL) COM BASE NO MODELO PRESSÃO ESTADO IMPACTO RESPOSTA (PEIR)
}

\section{ENVIRONMENTAL IMPACT ASSESSMENT IN THE ESTUARIES OF THE REGIONS CARAVELAS AND MUCURI (BA-BRAZIL) BASED ON MODEL PRESSURE STATE IMPACT RESPONSE (PSIR)}

\author{
Ester Gomes da Silva \\ Universidade do Estado do Rio de Janeiro - UERJ \\ Elenice Rachid da Silva \\ Programa de Engenharia de Transportes da Coppe/UFRJ \\ Josimar Ribeiro de Almeida \\ Universidade do Estado do Rio de Janeiro - UERJ \\ Universidade de São Paulo - USP
}

\section{RESUMO}

As regiões de Caravelas e Mucuri estão localizadas no Extremo Sul do estado da Bahia, são caracterizadas por serem regiões costeiras com ecossistemas variados que possuem grande importância no ciclo de vida de muitas espécies. São regiões que se destacam como os dois principais municípios produtores de Celulose no país. Na região de Caravelas está situado um dos principais parques marinhos da América do Sul, o Parque Nacional Marinho dos Abrolhos que possui grande importância na preservação de muitas espécies e, infelizmente vem sofrendo impactos ambientais devido ao grande crescimento do turismo e da pesca. Nos últimos anos essas duas regiões tem sido alvo de grandes atividades como monocultura de eucalipto, indústrias de papel e celulose, entre outras atividades que tem gerado emprego para os moradores locais e fonte de renda. Foi realizado um levantamento bibliográfico das duas regiões ao longo dos últimos anos com o intuito de atualizar as informações que foram previamente concedidas como por exemplo, crescimento populacional, dados de saneamento básico, entre outros, para analisar as mudanças ocorridas nas duas regiões e avaliar a intensidade dos impactos ambientais causados nas duas regiões. Através desse estudo pode ser observado que as duas regiões vêm apresentando expansão nos últimos anos e são regiões com grande viabilidade de implementação de grandes indústrias e aumento do turismo, implementação de resorts e hotéis, que tem causado mudanças em toda a paisagem e em parte gerando impactos ambientais que devem ser avaliados e estudados.

Palavras-Chaves: Caravelas, Mucuri, Impacto ambiental, PEIR, Estuário, Celulose. 


\begin{abstract}
The regions of Caravelas and Mucuri are located in the extreme south of Bahia state, they are characterized by coastal regions with diverse ecosystems that have great importance in the life of many species cycle. They are regions that stand out as the two main cellulose producing municipalities in the country. In Caravelas region it is situated one of the leading marine parks in South America, the Abrolhos Marine National Park which has great importance in the conservation of many species and unfortunately has suffered environmental damage due to the large growth of tourism and fishing. In recent years these two regions has been the subject of great activities such as eucalyptus monoculture, cellulose and paper industries, among other activities that have generated employment for local residents and source of income. It was conducted a literature review of the two regions over the last few years in order to update the information that was previously granted such as population growth, basic sanitation data, among others, to analyze the changes in the two regions and to assess the intensity of environmental impacts in both regions. Through this study it could be observed that the two regions has shown growth in recent years and they are areas with high feasibility of implementing major industries and increased tourism, implementation of resorts and hotels, which has caused changes across the landscape and generating part environmental impacts that must be assessed and studied.
\end{abstract}

Key words: Caravelas, Mucuri, Environment Impact, PSIR, Estuaries, Cellulose.

\title{
INTRODUÇÃO
}

Estuários podem ser caracterizados como regiões costeiras em que ocorre a transição entre o mar e o rio onde a água do mar é diluída pela água doce. (HAVENS, 2015).

São muito importantes como local de desova para várias espécies de crustáceo, peixes, entre outros, tendo assim um papel crucial nas atividades econômicas como pesca e turismo. (SIMÕES, 2012).

As regiões costeiras possuem ecossistemas que exercem importantes funções reguladoras, tem se observado que essas regiões estão sob grandes pressões devido à ocupação inadequada e a exploração inadequada de seus ecossistemas.

Essas regiões costeiras apresentam grande fragilidade ambiental como os estuários e manguezais, pois são áreas que estão sofrendo fortes influências das atividades humanas que muitas vezes acarretam em grandes impactos (HAVENS, 2015).

As regiões de Caravelas e Mucuri vêm sendo alvo de especulação imobiliária, grande crescimento do turismo, estabelecimento de indústrias entre outras atividades antrópicas. 
Essas duas regiões possuem o bioma Mata Atlântica, são regiões costeiras que abrigam diferentes ecossistemas e possuem importante papel na manutenção e sobrevivência de muitas espécies.

O ecossistema é formado por um conjunto de seres vivos que o habitam e interagem entre si em uma determinada área (FIOCRUZ, 2014). O Ecossistema apresenta funções, produtos e atributos que juntos contribuem para a diversidade encontrada no ecossistema e também para as atividades antrópicas que usufruem dos recursos encontrados no ecossistema.

As funções do ecossistema permitem um melhor entendimento da dinâmica do ecossistema, incluem as interações com os elementos estruturais de um ecossistema. (DAILY, 1997).

Os produtos do ecossistema são os recursos naturais usados pelo homem para diversas atividades.

Os atributos ambientais podem ser utilizados para o desenvolvimento de diversas atividades.

De acordo com ALMEIDA(2014) os ativos ambientais são coleções dos recursos naturais (como água, ar, solo etc.) prestadores de serviços ecológicos e que podem ser usados para consumo da sociedade.

\section{OBJETIVO}

Avaliar os impactos ambientais causados ao ambiente das regiões de Caravelas e Mucuri devido às atividades humanas e que medidas podem ser tomadas para reduzir esses impactos.

\section{Objetivo específico}

Identificar os danos ambientais nas duas regiões através do uso de ferramentas estatísticas que forneçam dados populacionais e de toda infraestrutura das duas regiões e através do modelo de Pressão Estado Impacto Resposta (PEIR). 


\section{HIPÓTESE}

Mediante a análise bibliográfica levantada foi observado que a região de Caravelas tem tido um crescimento populacional pequeno ao longo dos últimos dez anos, uma das hipóteses levantadas nesse estudo é: A atividade de monocultura de eucalipto na região de Caravelas possui relação direta com a diminuição no crescimento populacional.

\section{METODOLOGIA}

Foi realizado um levantamento bibliográfico referente ás duas regiões com o objetivo de atualizar as informações que foram previamente concedidas para um estudo comparativo das mudanças ocorridas nas duas regiões ao longo dos anos.

$O$ presente trabalho teve como base a teoria Pressão-Estado-ImpactoResposta (PEIR) que pode ser aplicada na análise de impactos ambientais. Nesse esquema pode se observar os principais pontos da teoria.

Figura 1.PEIR

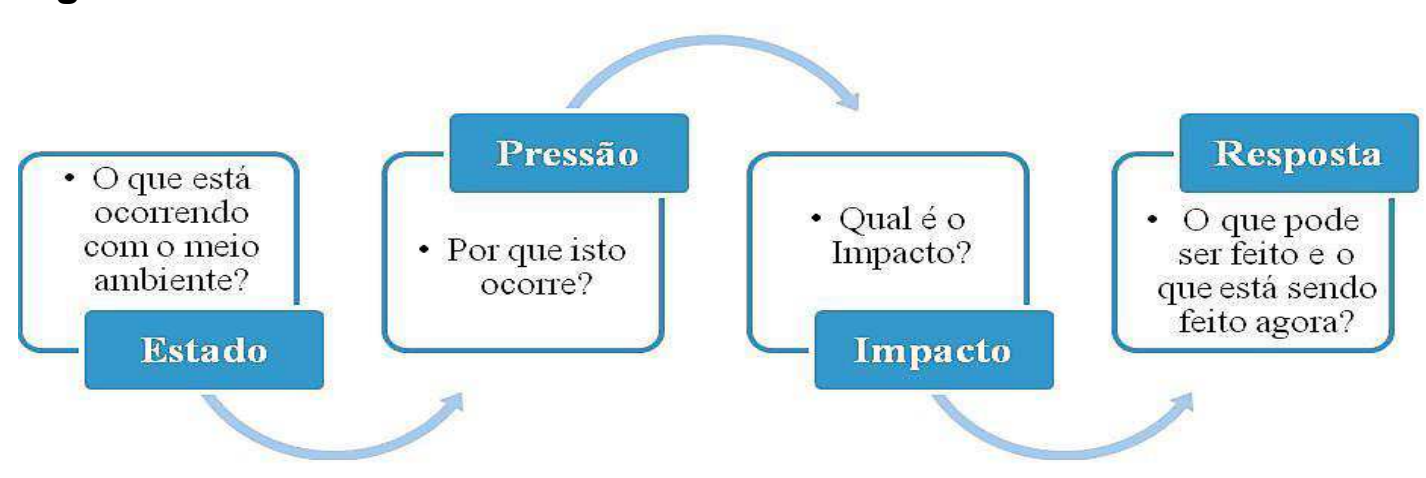

Fonte: IBAMA, 2015

Onde:

Pressão representa as pressões que as atividades antrópicas causam sobre o ambiente como forças econômicas, sociais, entre outras;

Estado indica como o ambiente se apresenta naquele momento, suas condições mediante aquela pressão que está sendo exercida sobre ele;

Impacto representa o resultado da pressão da ação antrópica exercida sobre 
o ambiente;

Resposta representa as medidas que podem ser tomadas para reduzir ou anular o impacto causado ao ambiente.

Esse modelo é muito vantajoso, pois ele mostra todos os componentes do problema causado ao ambiente, ele não expõe apenas o problema, mas também mostra o que as pressões exercidas no ambiente, o que causou o problema, as medidas que podem ser tomadas para reverter esse impacto, ou seja, ele confere toda uma análise do problema (BARCELLOS, 2013).

A metodologia se baseou na análise detalhada das funções, produtos e atributos encontrados na região de Caravelas tem tido um crescimento populacional pequeno ao longo dos últimos dez anos, uma das hipóteses levantadas nesse estudo é de que a atividade de monocultura de eucalipto realizada grandemente na região de Caravelas pode ter influência nessa diminuição do crescimento populacional visto que essa atividade exige uma área muito grande para execução, inviabilizando essas áreas para moradia, com isso as pessoas se deslocam para outros municípios onde possam construir moradia.

Tabela 1.Funções dos ecossistemas costeiros brasileiros

\begin{tabular}{|c|c|c|c|c|c|c|c|c|c|c|}
\hline & $\begin{array}{l}\text { Baías, } \\
\text { estuários } \\
\text { e deltas }\end{array}$ & Mangues & $\begin{array}{l}\text { Dunas e } \\
\text { Falésias }\end{array}$ & $\begin{array}{c}\text { Recifes } \\
e \\
\text { corais }\end{array}$ & $\begin{array}{c}\text { Lagunas } \\
\text { e } \\
\text { Banhados }\end{array}$ & $\begin{array}{l}\text { Planícies } \\
\text { Intermarés }\end{array}$ & $\begin{array}{l}\text { Praias } \\
e \\
\text { costões }\end{array}$ & $\begin{array}{c}\text { Ilhas e } \\
\text { Arquipélagos }\end{array}$ & $\begin{array}{l}\text { Planícies } \\
\text { fluviais }\end{array}$ & $\begin{array}{l}\text { Vegetação } \\
\text { e florestas }\end{array}$ \\
\hline $\begin{array}{l}\text { 1. Águas } \\
\text { abrigadas }\end{array}$ & $\mathrm{F}$ & - & - & A & $P$ & - & - & $P$ & - & - \\
\hline $\begin{array}{l}\text { 2. Águas } \\
\text { subterrâneas }\end{array}$ & A & A & $P$ & - & $\mathrm{F}$ & A & - & $P$ & $\mathrm{~F}$ & A \\
\hline $\begin{array}{l}3 . \\
\text { Exportação } \\
\text { de biomassa }\end{array}$ & $\mathrm{P}$ & $\mathrm{F}$ & A & $\mathrm{F}$ & $\mathrm{F}$ & $\mathrm{F}$ & $\mathrm{P}$ & - & $P$ & $\mathrm{~F}$ \\
\hline $\begin{array}{l}\text { 4. Fonte de } \\
\text { nutrientes }\end{array}$ & $\mathrm{P}$ & $\mathrm{F}$ & - & $\mathrm{F}$ & $\mathrm{F}$ & $\mathrm{F}$ & - & A & $\mathrm{F}$ & $\mathrm{F}$ \\
\hline $\begin{array}{l}\text { 5. Fonte de } \\
\text { sedimentos }\end{array}$ & $P$ & A & $\mathrm{F}$ & A & - & $F$ & $\mathrm{~F}$ & A & $\mathrm{F}$ & - \\
\hline $\begin{array}{l}\text { 6. Prevenção } \\
\text { de erosão }\end{array}$ & $\mathrm{P}$ & $\mathrm{F}$ & $\mathrm{P}$ & $P$ & $\mathrm{P}$ & $P$ & $P$ & $P$ & $\mathrm{~F}$ & $F$ \\
\hline $\begin{array}{l}\text { 7. Prevenção } \\
\text { de } \\
\text { inundação }\end{array}$ & $\mathrm{P}$ & $\mathrm{F}$ & A & - & $\mathrm{P}$ & $\mathrm{F}$ & A & - & $\mathrm{F}$ & $\mathrm{P}$ \\
\hline $\begin{array}{l}\text { 8. Proteção } \\
\text { de } \\
\text { tempestades }\end{array}$ & $\mathrm{P}$ & $\mathrm{F}$ & $P$ & $P$ & $P$ & A & $\mathrm{F}$ & $P$ & A & - \\
\hline $\begin{array}{l}\text { 9. Retenção } \\
\text { de nutrientes }\end{array}$ & $\mathrm{P}$ & $\mathrm{F}$ & - & $\mathrm{F}$ & - & $\mathrm{F}$ & $\mathrm{P}$ & - & $\mathrm{F}$ & $\mathrm{F}$ \\
\hline
\end{tabular}




\begin{tabular}{|c|c|c|c|c|c|c|c|c|c|}
\hline $\begin{array}{l}\text { 10. Retenção } \\
\text { de } \\
\text { sedimentos }\end{array}$ & $F$ & $F$ & $P$ & A & $F$ & $F$ & $P$ & A & $F$ \\
\hline $\begin{array}{l}\text { 11. Via de } \\
\text { transporte }\end{array}$ & $P$ & $P$ & A & $A$ & $F$ & $P$ & $A$ & $F$ & $F$ \\
\hline
\end{tabular}

Fonte: ALMEIDA, 2014

Tabela 2. Produtos dos ecossistemas costeiros brasileiros

\begin{tabular}{|c|c|c|c|c|c|c|c|c|c|c|}
\hline & $\begin{array}{c}\text { Baias,estuários } \\
\text { e deltas }\end{array}$ & Mangues & $\begin{array}{l}\text { Dunas } \\
\text { e } \\
\text { falésias }\end{array}$ & $\begin{array}{c}\text { Recifes } \\
\text { e } \\
\text { corais }\end{array}$ & $\begin{array}{c}\text { Lagunas } \\
\mathrm{e} \\
\text { banhados }\end{array}$ & $\begin{array}{l}\text { Planícies } \\
\text { intermarés }\end{array}$ & $\begin{array}{l}\text { Praias } \\
\text { e }\end{array}$ & $\begin{array}{c}\text { Ilhas e } \\
\text { arquipélagos }\end{array}$ & $\begin{array}{l}\text { Planícies } \\
\text { fluviais }\end{array}$ & $\begin{array}{l}\text { Vegetação } \\
\text { e florestas }\end{array}$ \\
\hline 1.Aquicultura & $A$ & A & - & - & $\mathrm{P}$ & $\mathrm{P}$ & $A$ & - & $P$ & - \\
\hline $\begin{array}{l}\text { 2.Campos e } \\
\text { pastagens }\end{array}$ & $P$ & $P$ & - & - & $\mathrm{P}$ & $\mathrm{F}$ & $A$ & $\mathrm{P}$ & $F$ & $\mathrm{~F}$ \\
\hline $\begin{array}{l}\text { 3.Espécies } \\
\text { Silvestres }\end{array}$ & $\mathrm{F}$ & $\mathrm{P}$ & $\mathrm{P}$ & - & $\mathrm{P}$ & $\mathrm{F}$ & $P$ & $P$ & $\mathrm{~F}$ & $\mathrm{~F}$ \\
\hline $\begin{array}{l}\text { 4.Recreação } \\
\text { e turismo }\end{array}$ & $P$ & $P$ & $P$ & $\mathrm{~F}$ & $\mathrm{~F}$ & $\mathrm{P}$ & $\mathrm{F}$ & $\mathrm{F}$ & $P$ & $P$ \\
\hline $\begin{array}{l}\text { 5.Recursos } \\
\text { pesqueiros }\end{array}$ & $\mathrm{F}$ & $\mathrm{F}$ & - & $\mathrm{F}$ & - & $\mathrm{F}$ & $P$ & $\mathrm{~F}$ & $\mathrm{~F}$ & - \\
\hline $\begin{array}{l}\text { 6.Recursos } \\
\text { agrícolas }\end{array}$ & $A$ & $A$ & - & - & $P$ & $\mathrm{~F}$ & $A$ & $P$ & $P$ & $A$ \\
\hline $\begin{array}{l}\text { 7.Recursos } \\
\text { minerais }\end{array}$ & $P$ & A & $P$ & $\mathrm{P}$ & $\mathrm{P}$ & $\mathrm{P}$ & $P$ & $P$ & $\mathrm{P}$ & A \\
\hline $\begin{array}{l}\text { 8.Recursos } \\
\text { florestais }\end{array}$ & $A$ & $\mathrm{~F}$ & - & - & - & $P$ & $A$ & - & $A$ & $\mathrm{~F}$ \\
\hline
\end{tabular}

Fonte: ALMEIDA, 2014

Tabela 3. Atributos dos ecossistemas costeiros brasileiros

\begin{tabular}{|c|c|c|c|c|c|c|c|c|c|c|}
\hline & $\begin{array}{l}\text { Baías, } \\
\text { estuários e } \\
\text { deltas }\end{array}$ & Mangues & $\begin{array}{c}\text { Dunas } \\
e \\
\text { falésias }\end{array}$ & $\begin{array}{c}\text { Recifes } \\
\text { e } \\
\text { corais }\end{array}$ & $\begin{array}{c}\text { Lagunas } \\
e \\
\text { banhados }\end{array}$ & $\begin{array}{l}\text { Planícies } \\
\text { intermarés }\end{array}$ & $\begin{array}{l}\text { Praias } \\
e \\
\text { costões }\end{array}$ & $\begin{array}{l}\text { Ilhas e } \\
\text { arquipélagos }\end{array}$ & $\begin{array}{l}\text { Planícies } \\
\text { fluviais }\end{array}$ & $\begin{array}{l}\text { Vegetação } \\
\text { e florestas }\end{array}$ \\
\hline $\begin{array}{l}\text { 1. Diversidade } \\
\text { biológica }\end{array}$ & $\mathrm{F}$ & $P$ & - & $\mathrm{F}$ & $F$ & $F$ & $\mathrm{P}$ & $\mathrm{F}$ & $P$ & $\mathrm{~F}$ \\
\hline $\begin{array}{l}\text { 2. Diversidade } \\
\text { e Patrimônio } \\
\text { cultural }\end{array}$ & $P$ & $P$ & - & - & $\mathrm{F}$ & $\mathrm{P}$ & $P$ & $\mathrm{~F}$ & $\mathrm{P}$ & - \\
\hline $\begin{array}{l}\text { 3. Morfologia } \\
\text { epaisagens }\end{array}$ & $P$ & A & $\mathrm{F}$ & $\mathrm{F}$ & $\mathrm{P}$ & A & - & $\mathrm{F}$ & $A$ & $\mathrm{~F}$ \\
\hline
\end{tabular}

Fonte: ALMEIDA, 2014 
Nas tabelas 1, 2 e 3: $\mathrm{F}=$ Frequente e importante; $\mathrm{P}=$ Presente; $\mathrm{e} \mathrm{A}=$ Ausente e raro.

Seus ecossistemas exercem importantes papeis no ambiente, a tabela a seguir proposta por ALMEIDA (2014) mostra as funções dos ecossistemas das duas regiões:

Tabela 4. Funções do ecossistema na Região dos Estuários de Caravelas e Mucuri

\begin{tabular}{|c|c|c|c|c|c|c|c|c|c|c|}
\hline Área & $\begin{array}{c}\text { Pesca } \\
\text { artesanal } \\
\mathrm{X} \\
\text { Indústria }\end{array}$ & $\begin{array}{c}\text { Turismo } \\
\mathrm{X} \\
\text { Comunidade } \\
\text { local }\end{array}$ & $\begin{array}{c}\text { Monocultura } \\
\text { X } \\
\text { Pequena } \\
\text { produção }\end{array}$ & $\begin{array}{c}\text { Garimpo } \\
\text { X } \\
\begin{array}{c}\text { População } \\
\text { local }\end{array}\end{array}$ & $\begin{array}{c}\text { Salineiros } \\
\text { X } \\
\text { Pescadores }\end{array}$ & $\begin{array}{c}\text { Aquicultura } \\
\text { X } \\
\text { Pescadores }\end{array}$ & $\begin{array}{c}\text { Pecuária } \\
\text { X } \\
\text { Pequena } \\
\text { Produção }\end{array}$ & $\begin{array}{c}\text { Pescadores } \\
\mathrm{X} \\
\text { Empresa } \\
\text { Petrolífera }\end{array}$ & $\begin{array}{c}\text { UC } \\
\text { X } \\
\text { População } \\
\text { tradicional }\end{array}$ & $\begin{array}{l}\text { Usos } \\
\text { de } \\
\text { água }\end{array}$ \\
\hline $\begin{array}{c}\text { Estuários } \\
\text { Caravelas/ } \\
\text { Mucuri }\end{array}$ & $P$ & $P$ & $P$ & - & - & - & - & - & $P$ & - \\
\hline
\end{tabular}

Fonte: ALMEIDA, 2014

O Ecossistema também apresenta produtos que são os recursos naturais que podem ser utilizados de diferentes maneiras, podendo contribuir para 0 desenvolvimento econômico das regiões. A segunda tabela também proposta por ALMEIDA (2014) mostra os produtos do ecossistema e suas relações com as atividades econômicas.

Tabela 5.Produtos do ecossistema na Região dos Estuários de Caravelas e Mucuri

\begin{tabular}{|c|c|c|c|c|c|c|c|c|c|c|}
\hline Área & $\begin{array}{l}\text { Baías, } \\
\text { estuários } \\
\text { e deltas }\end{array}$ & Mangues & $\begin{array}{c}\text { Dunas } \\
\text { e } \\
\text { falésias }\end{array}$ & $\begin{array}{c}\text { Recifes } \\
\text { e } \\
\text { corais }\end{array}$ & $\begin{array}{c}\text { Lagunas } \\
\text { e } \\
\text { banhados }\end{array}$ & $\begin{array}{l}\text { Planícies } \\
\text { intermarés }\end{array}$ & $\begin{array}{c}\text { Praias } \\
\text { e } \\
\text { costões }\end{array}$ & $\begin{array}{c}\text { Ilhas e } \\
\text { arquipélagos }\end{array}$ & $\begin{array}{l}\text { Planícies } \\
\text { fluviais }\end{array}$ & $\begin{array}{l}\text { Vegetação } \\
\text { e florestas }\end{array}$ \\
\hline $\begin{array}{c}\text { Estuários } \\
\text { Caravelas/ } \\
\text { Mucuri }\end{array}$ & 4 & 6,4 & $\mathrm{SD}$ & 5 & $\mathrm{SD}$ & SD & 4 & SD & 8,6 & 6,8 \\
\hline
\end{tabular}

Legenda:Produtos do ecossistema:1. Aquicultura; 2. Campos e Pastagens; 3. Espécies Silvestres; 4. Recreação e Turismo; 5. Recursos Pesqueiros; 6. Recursos Agrícolas; 7. Recursos Minerais; 8. Recursos Florestais e Vegetais; SD. Sem dados.

Fonte: ALMEIDA, 2014 


\section{CARACTERIZAÇÃO E DESCRIÇÃO DO LOCAL}

As regiões de Caravelas e Mucuri se situam no extremo Sul do estado da Bahia que compreende cerca de 21 municípios.

Figura 2.Extremo sul da Bahia

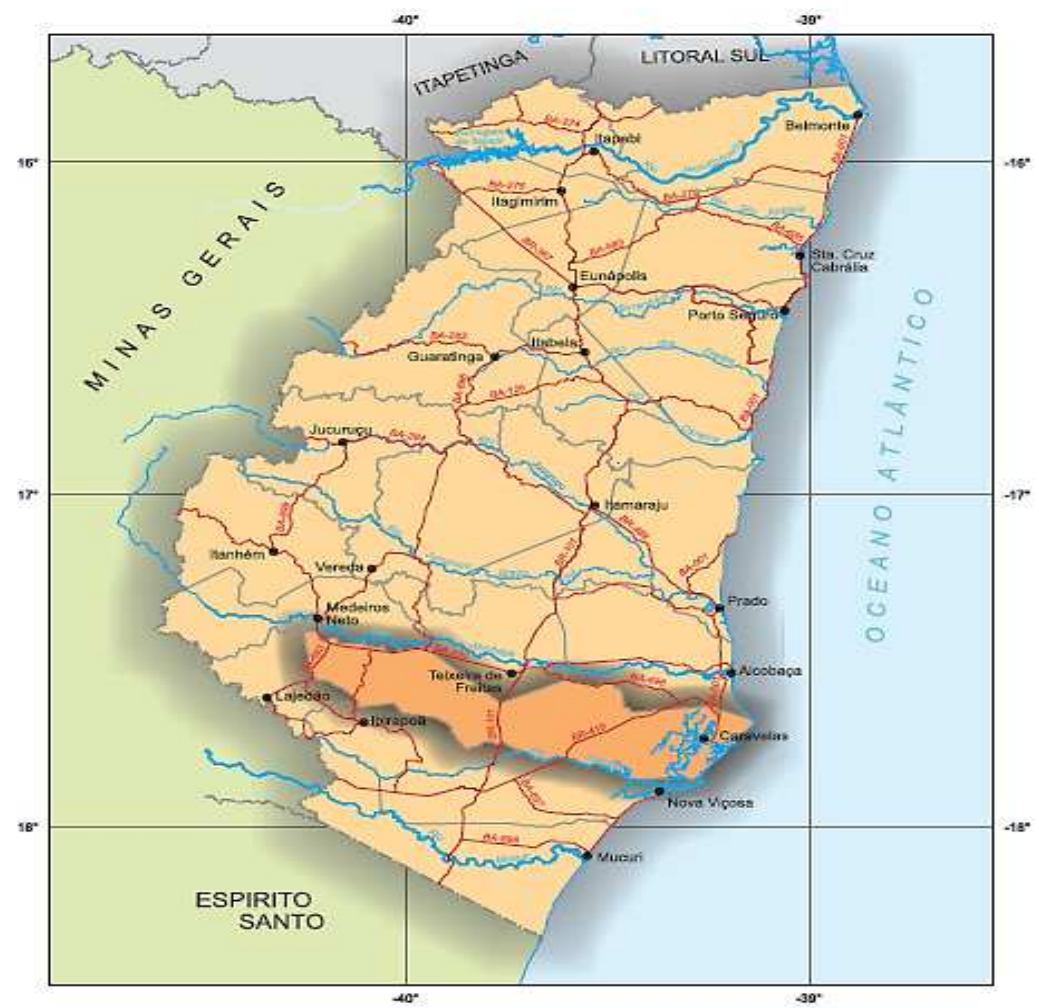

Fonte: SEI, 2010

\section{Caravelas (17ㄴ3'55”'S; 3933'03”' W)}

Apresenta um clima úmido a subúmido com temperatura média anual de $24^{\circ} \mathrm{C}$, a vegetação da região é formada por floresta Ombrófila densa e formações pioneiras com influência fluviomarinha (mangue). 
Figura 3.Caravelas

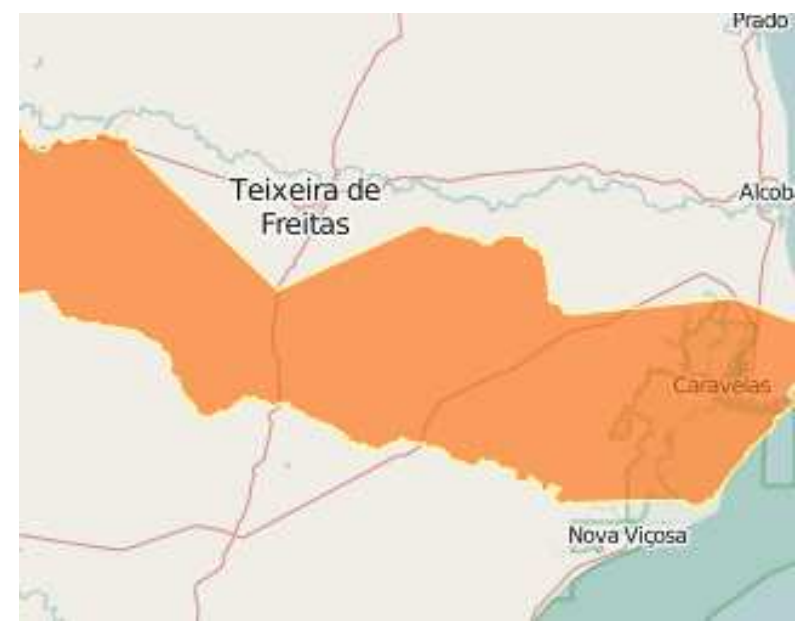

Fonte: IBGE, 2015

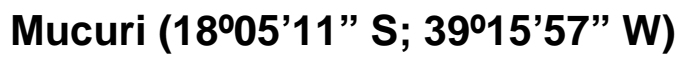

Apresenta um clima úmido a subúmido com temperatura média anual de $24^{\circ} \mathrm{C}$, vegetação formada por Floresta Ombrófila Densa, os principais rios da região são Rio Mucuri, Rio Mucurizinho, Córrego Palmital, Rio Peruípe do Sul e Rio Pau Alto, a região apresenta a APA da Costa Dourada e a RPPN Adília Paraguaçu Batista.

Figura 4.Mucuri

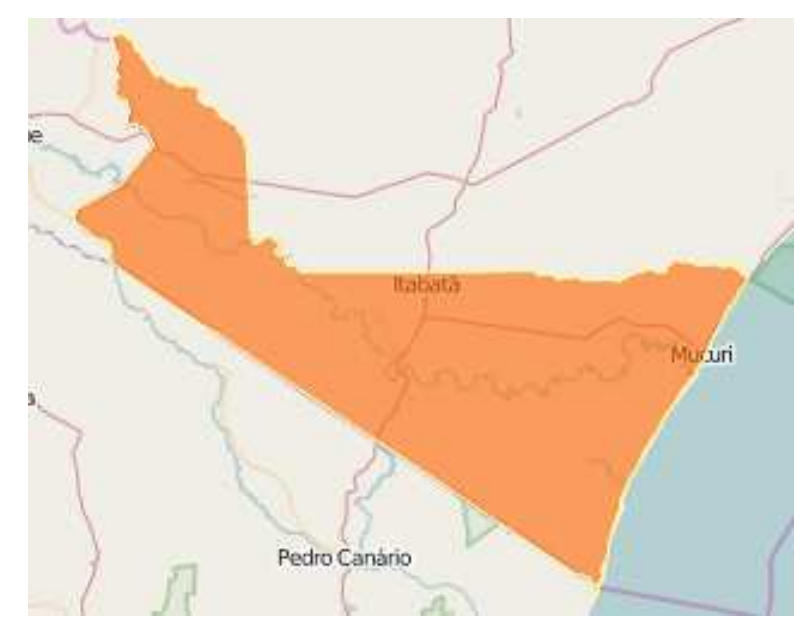

Fonte: IBGE, 2015 
Tabela 6.Densidade demográfica e área de unidade territorial das regiões de acordo com o Censo demográfico de 2010

\begin{tabular}{ccc}
\hline Regiões & $\begin{array}{c}\text { Densidade } \\
\text { demográfica } \\
\text { (Hab./km2) }\end{array}$ & $\begin{array}{c}\text { Área de unidade } \\
\text { Territorial }\left(\mathbf{k m}^{2}\right)\end{array}$ \\
\hline Caravelas & 8,95 & $2.396,608$ \\
Nova Viçosa & 29,15 & $1.317,396$ \\
Mucuri & 20,23 & $1.786,496$ \\
\hline
\end{tabular}

Fonte: IBGE, Censo 2010

Figura 5.Localização geográfica entre as três regiões

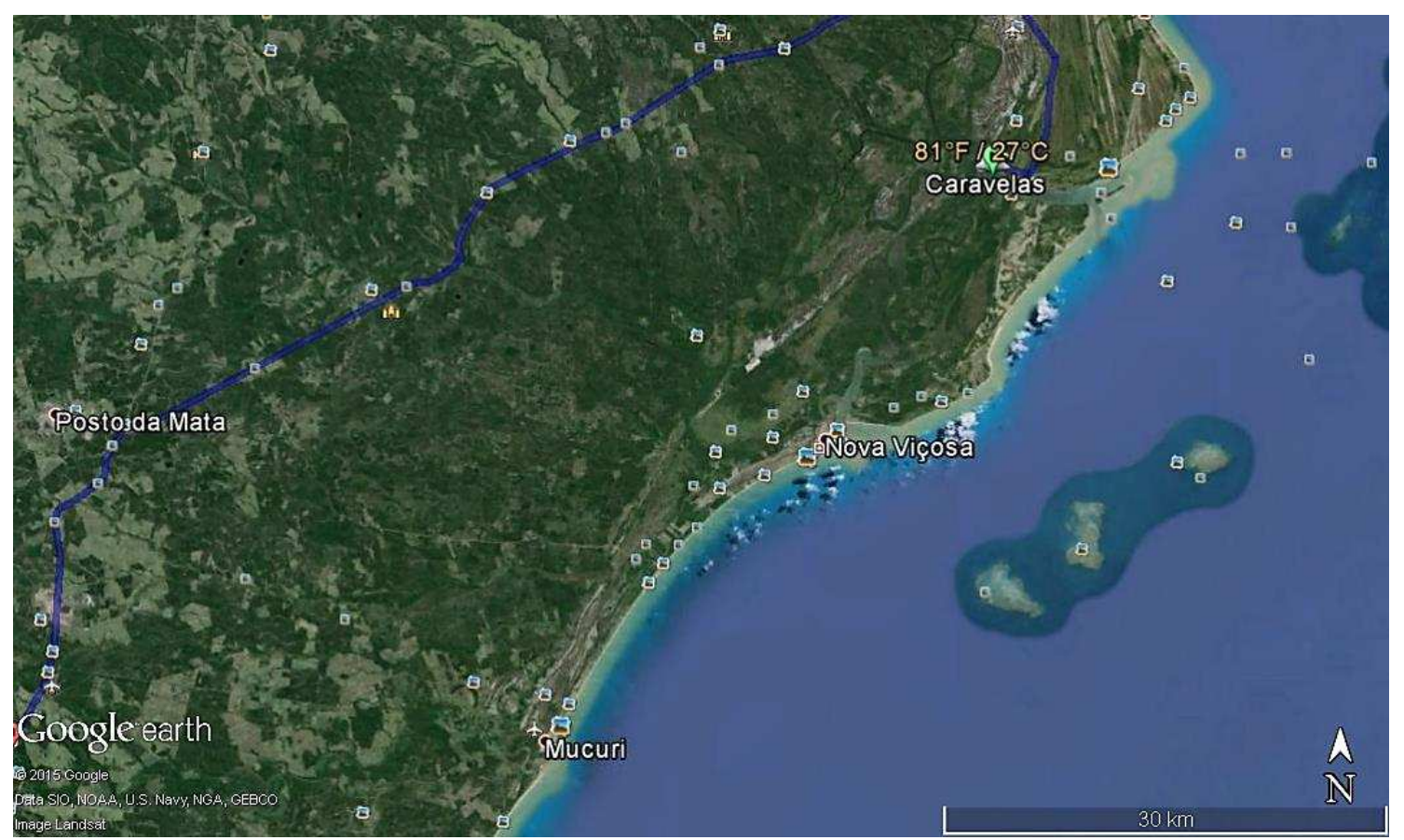

Fonte: GOOGLE EARTH, 2015

\section{Unidades de Conservação}

Reserva Extrativista de Cassurubá

A região de Caravelas possui grande importância ambiental relacionada diretamente com o Parque Nacional Marinho dos Abrolhos que é um dos principais da América do Sul e que vem sofrendo ameaças devido ao grande crescimento do 
turismo e da pesca.

No ano de 2009 foi liberado o decreto para a criação da Reserva Extrativista de Cassurubá, a Resex. De acordo com o Instituto Chico Mendes (ICMBio) a reserva apresenta uma área de 100.767,56 hectares e se estendo pelos municípios de Caravelas, Alcobaça e Nova Viçosa. De acordo com o Relatório Parametrizado emitido pela ICMBio, o principal objetivo dessa Unidade de Conservação é:

"Proteger os meios de vida e garantir a utilização e a conservação dos recursos naturais renováveis tradicionalmente utilizados pela população extrativista residente na área de sua abrangência".

A Reserva atende a cerca de 20.000 famílias que dependem da pesca nessa região (SOUZA,2013). A pesca nessa reserva é realizada para o consumo das comunidades locais e para uma venda em pequena escala e obedecem ao conselho deliberativo criado pela Resex, ela é feita de forma sustentável levando em conta o período de defeso dos peixes e caranguejos que seria o período de reprodução dessas espécies (ICMBio).

\section{$\underline{\text { Reserva Extrativista de Cassurubá }}$}

De acordo com o Instituto de Meio Ambiente e Recursos Hídricos a APA ponta da baleia se localiza nos municípios de Alcobaça e Caravelas e possui 34.600 ha.

Essa APA é de grande importância para conservação de espécies ameaçadas de extinção como a Baleia Jubarte que visita a região anualmente para reprodução, também é importante para o ecoturismo local.

\section{RESULTADOS}

A tabela a seguir mostra os dados atualizados retirados do Instituto Brasileiro de Geografia e Estatística-IBGE referente ao crescimento populacional nas regiões. 
Tabela 7.Crescimento nas regiões nos últimos anos

\begin{tabular}{|c|c|c|c|c|c|c|c|c|c|c|c|c|c|}
\hline \multirow{2}{*}{$\begin{array}{l}\text { Região de } \\
\text { Caravelas } \\
\text { e Mucuri }\end{array}$} & \multicolumn{2}{|l|}{1980} & \multicolumn{2}{|l|}{1991} & \multicolumn{3}{|l|}{1993} & \multicolumn{2}{|l|}{1996} & \multicolumn{2}{|l|}{2000} & \multicolumn{2}{|l|}{2010} \\
\hline & $\begin{array}{l}\text { População } \\
\text { Total }\end{array}$ & $\begin{array}{l}\% \\
\text { Urbana }\end{array}$ & $\begin{array}{l}\text { Populaçã } \\
\text { o Total }\end{array}$ & \% Urbana & $\begin{array}{l}\text { Populaç } \\
\text { ão Total }\end{array}$ & $\begin{array}{l}\text { Incremento } \\
91-93(\%)\end{array}$ & $\begin{array}{l}\text { Densidade } \\
\left(\mathrm{Hab} . / \mathrm{km}^{2}\right)\end{array}$ & $\begin{array}{l}\text { População } \\
\text { Total }\end{array}$ & $\begin{array}{l}\text { Increment } \\
0 \\
93-96(\%)\end{array}$ & $\begin{array}{l}\text { Populaçã } \\
\text { o Total }\end{array}$ & $\begin{array}{l}\text { \%Urba } \\
\text { na }\end{array}$ & $\begin{array}{l}\text { Populacao } \\
\text { Total }\end{array}$ & $\begin{array}{l}\% \\
\text { Urbana }\end{array}$ \\
\hline Caravelas & & & 19.763 & 45,2 & 19.818 & 0,14 & 8,3 & 18.613 & & 20.103 & & 21.414 & 52,00 \\
\hline $\begin{array}{l}\text { Nova } \\
\text { Viçosa }\end{array}$ & 18.911 & 32,5 & 25.570 & 36,6 & 27.162 & 3 & 20,4 & 27.088 & & 32.076 & & 38.556 & 86,00 \\
\hline Mucuri & 15.416 & 18,7 & 17.606 & 27,3 & 17.888 & 0,8 & 10 & 22.851 & & 28.062 & & 36.026 & 76,00 \\
\hline
\end{tabular}

Fonte: IBGE, 2015

A tabela a seguir ilustra a estimativa da população total de 2015 feita pelo Instituto Brasileiro de Geografia e Estatística (IBGE).

Tabela 8. População estimada para 2015 nas regiões

\begin{tabular}{lc}
\hline \multicolumn{1}{c}{ Regiões } & População total estimada para \\
& 2015 \\
\hline Caravelas & 22.548 \\
Nova Viçosa & 43.216 \\
Mucuri & 41.068 \\
\hline
\end{tabular}

Fonte: IBGE, 2015

A tabela a seguir mostra a porcentagem de cada um desses itens nas regiões. 
Tabela 9. Dados de Saneamento Básico nas regiões no ano de 2010

\begin{tabular}{lccc}
\hline $\begin{array}{l}\text { Região de } \\
\text { Caravelas e Mucuri }\end{array}$ & $\begin{array}{c}\text { \% Abastecimento } \\
\text { de Água }\end{array}$ & $\begin{array}{c}\text { \% Rede de } \\
\text { Esgoto }\end{array}$ & $\begin{array}{c}\text { \% Coleta } \\
\text { de Lixo }\end{array}$ \\
\hline Caravelas & 54,46 & 54,46 & 54,46 \\
Nova Viçosa & 60,1 & 87,65 & 87,65 \\
Mucuri & 87,65 & 77,46 & 77,46 \\
\hline
\end{tabular}

Fonte: SIDRA, 2015

Os dados foram retirados de tabelas localizadas na seção Séries Temporais do banco de dados Sidra.

Os dados de abastecimento de água foram retirados da Tabela 3263 que apresenta a situação dos domicílios urbanos em relação ao abastecimento de água. Os dados de rede de esgoto foram retirados da Tabela 3216 que demonstra a situação dos domicílios urbanos em relação a rede de esgoto.Os dados de destino do lixo foram retirados da Tabela 3217 que apresenta a situação dos domicílios urbanos em relação a rede de lixo.

Gráfico1.Crescimento populacional ao longo dos anos

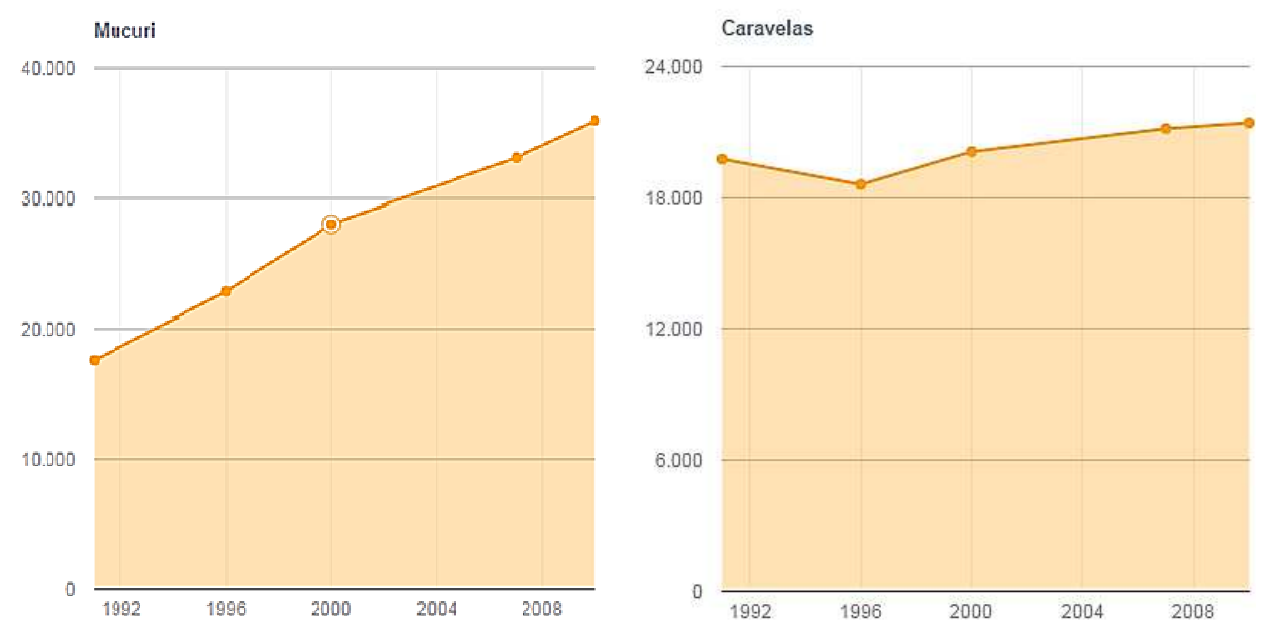

Fonte: IBGE, 2015 


\section{Economia}

Caravelas e Mucuri destacam-se como os dois principais municípios produtores de celulose do país. A agricultura e a pesca artesanal também apresentam papel muito importante na economia das duas regiões, grande parte do PIB arrecadado vem dessas duas atividades. O surgimento de novas indústrias e do crescente turismo tem garantido fonte de renda para os moradores da região, porém, todas essas atividades também geram impactos no meio ambiente que devem ser analisados a modo que possam ser reduzidos.

Os gráficos abaixo ilustram o PIB de cada região e torna evidente a grande diferença entre as duas regiões visto que em Caravelas grande parte do PIB provém da agricultura enquanto que em Mucuri é o setor industrial que é o responsável por grande parte do PIB. Um desses fatores é que em Caravelas tem grande atividade de agricultura, principalmente a monocultura do eucalipto. Em Mucuri estão instaladas grandes indústrias como a de papel e Celulose.

Gráfico2. Produto Interno Bruto (PIB)

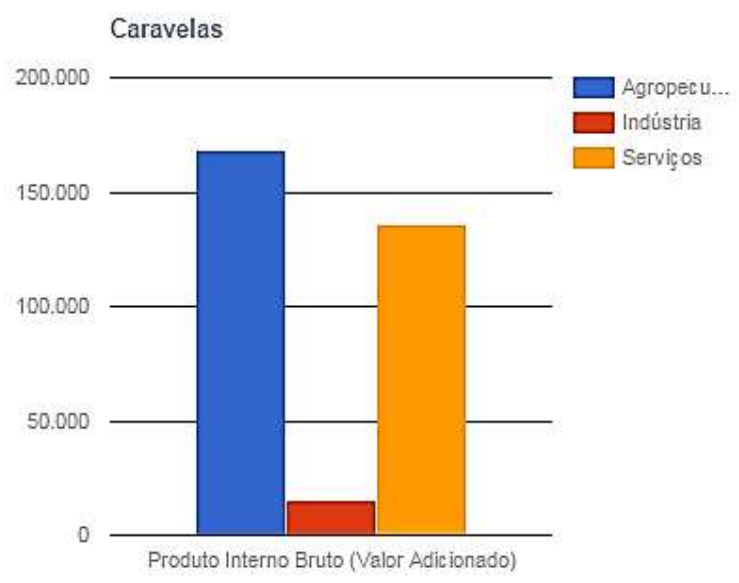




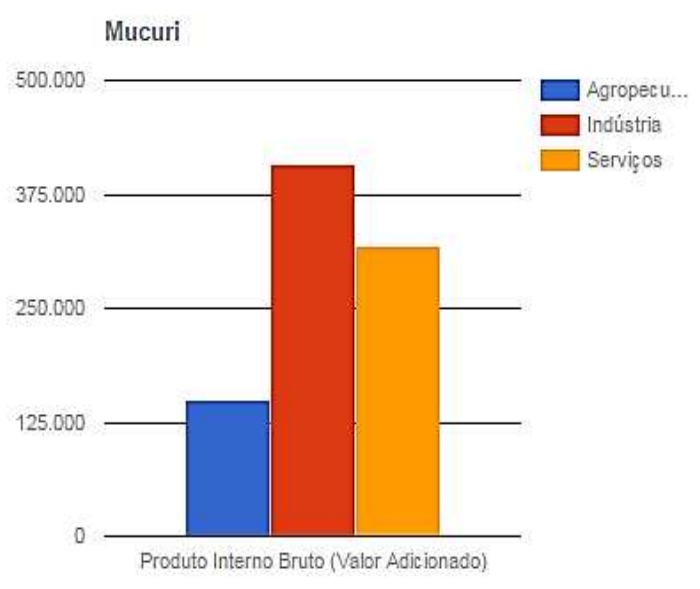

Fonte: IBGE, 2015

\section{RESULTADOS}

Devido à implantação de indústrias como a de papel e celulose, plantação de eucalipto e o aumento do turismo, pode se observar um crescimento populacional ocorrido nas duas regiões ao longo dos anos (SOUZA,2015). À medida que a população cresce, se faz necessário uma melhoria nas condições de saneamento básico incluindo coleta de lixo, rede de abastecimento de esgoto e rede de abastecimento de água.

Como pôde ser observado na tabela, ainda há uma grande deficiência de uma rede de esgoto eficiente nas regiões listadas, a maioria das famílias não possuem uma rede de esgoto apropriada, no estudo analisado foi obtido os dados que em Caravelas 69,3\% das casas possuem esgoto por fossa, em Mucuri são $64,7 \%$ das famílias com esgoto por fossa. Ou seja, os serviços de saneamento básico não têm acompanhado o crescimento populacional das regiões, o que pode acarretar em uma má qualidade de vida para os moradores.

Analisando a tabela e os gráficos pode se observar que a população de Mucuri teve um grande crescimento ao longo dos anos enquanto que a população de Caravelas vem adquirindo certa estabilidade com um crescimento menor. $\mathrm{O}$ estabelecimento de indústrias importantes como a de papel e celulose na região de Mucuri pode ser uma das causas para esse grande crescimento populacional, com a geração de empregos para os moradores locais incentivando-os a permanecerem no município. Por outro lado, a monocultura de eucalipto ocupa cerca de $90 \%$ do 
município fazendo com que ocorra uma grande concentração fundiária gerando a expulsão dos trabalhadores rurais para outras regiões(SOUZA,2015), além disso, a atividade tem causado grande problemas de saúde nos trabalhadores que tem sofrido com os agrotóxicos usados na atividade, tudo isso tem sido indicativo do pequeno crescimento que a região de Caravelas tem apresentado pois mediante a esses problemas, as pessoas acabam indo para outras regiões próximas em busca de empregos com melhor qualidade de vida e saúde.

\section{Conflitos ambientais}

A região de Caravelas e Mucuri têm sofrido alguns impactos ambientais devido às atividades de agricultura destacando-se a silvicultura de eucalipto que é uma prática que causa alguns impactos, também vem sofrendo impactos da indústria de papel e celulose.

Nos últimos anos o ramo agrícola vem crescendo grandemente e tem se observado uma redução na vegetação e nos manguezais. De acordo com SOUZA (2015) durante três períodos estudados $(1989,1991$ e 2006) as regiões de manguezais e brejos apresentaram uma redução de aproximadamente $18 \%$ o que se torna preocupante visto que esses ecossistemas são extremamente importantes para a sobrevivência e manutenção de muitas espécies, o possível motivo para essa redução seria para dar lugar a áreas que seriam usadas para agricultura, pastagens e até para áreas urbanas visto que tem sido observado um grande crescimento urbano e turístico nas duas regiões o que também demanda uma devastação de áreas de vegetação para implantação de casas e estabelecimentos.

\section{Uso da terra}

A região de Caravelas apresenta diversidades no uso de terra, como agricultura, áreas urbanas, entre outros. A tabela a seguir foi adaptada do trabalho de SOUZA (2015) e ilustra os diferentes usos do solo nessa região e se a atividade em questão está se expandindo ou se encontra em redução. 
Tabela 10.Uso da terra em Caravelas - BA

\begin{tabular}{lcccccccccc}
\hline & \multicolumn{3}{c}{1984} & \multicolumn{2}{c}{1991} & \multicolumn{2}{c}{2006} & \multicolumn{2}{c}{2011} & \\
\cline { 2 - 8 } $\begin{array}{l}\text { Tipos de } \\
\text { Uso }\end{array}$ & Área & Área & Área & Área & Área & Área & Área & Área & \\
& $\mathbf{( K m})$ & $(\%)$ & $(\mathrm{Km})$ & $\mathbf{( \% )}$ & $\mathbf{( K m})$ & $(\%)$ & $(\mathrm{Km})$ & $(\%)$ & Diagnósticos \\
\hline $\begin{array}{l}\text { Área } \\
\text { Florestal }\end{array}$ & 137,51 & 23,02 & 144,01 & 24,83 & 139,60 & 24,07 & 149,10 & 25,69 & expansão \\
$\begin{array}{l}\text { Manguezais } \\
\text { e Brejos }\end{array}$ & 164,21 & 28,14 & 93,20 & 16,07 & 59,04 & 10,18 & 80,04 & 13,80 & redução \\
$\begin{array}{l}\text { Área } \\
\text { agrícola }\end{array}$ & 44,37 & 7,65 & 65,03 & 10,35 & 135,48 & 23,36 & 63,68 & 10,98 & expansão \\
$\begin{array}{l}\text { Corpos } \\
\text { d'agua }\end{array}$ & 51,62 & 8,90 & 74,99 & 12,93 & 32,19 & 5,55 & 27,72 & 4,78 & redução \\
$\begin{array}{l}\text { Área } \\
\text { urbana }\end{array}$ & 15,42 & 2,66 & 16,82 & 2,90 & 20,3 & 3,50 & 26,44 & 4,56 & expansão \\
\hline
\end{tabular}

Fonte: Adaptado de SOUZA, 2015

Observando a tabela se depreende que as áreas agrícolas tiveram uma queda mas ainda tendem à expansão, manguezais e corpos d'agua tendem a uma redução como havia sido dito anteriormente devido ao uso da terra para pastagem e plantio, as áreas florestais têm se expandido devido a implantação da Resex que tem como um de seus papeis a proteção dessas áreas florestais.

\section{CONCLUSÃO}

Através do levantamento bibliográfico pôde ser observado que ambas regiões vem apresentando expansão nos últimos anos e têm se mostrado como regiões com grande viabilidade de implementação de grandes indústrias que tem causado uma grande mudança em toda a paisagem nas duas regiões, áreas de mangues e brejos vem apresentando uma redução devido a prática de monocultura de eucalipto, grandes áreas de campo vem sendo ocupadas por essa atividade, além disso a indústria do turismo também vem gerando mudanças com a 
implementação de resorts e hotéis, tudo isso causa impactos ambientais que devem ser avaliados e estudados. Muitas mudanças ainda precisam ser feitas nas regiões como melhoramento do saneamento básico e nas condições de vida dos moradores das duas regiões pois muitos ainda não usufruem das básicas condições de vida que devem ser proporcionadas pelo governo.

\section{REFERÊNCIAS BIBLIOGRÁFICAS}

BARCELlos, F. C., OliVeiRA, S. M. M., CARVALHO, P. G. M., e GREEN, A. L. Diagnóstico ambiental dos municípios segundo o modelo Pressão-Estado-ImpactoResposta, p:03-04, 2013. Disponível em: $<$ http://www.pos.ajes.edu.br/arquivos/referencial 20121205104533.pdf>. Acesso em: 08/04/2016.

COELHO, P.M.R. e HAVENS, K. Crise nas águas. 2015.1 edição, Editora Recóleo.Disponível em:<http://flseagrant.ifas.ufl.edu/CriseNasAguas/FrontMatterandPreface.pdf $>$. Acesso em: 06/11/2015.

DAILY, C.G. Nature's Services: Societal Dependence on Natural Ecosystems. Washington, Island Press, 412p, 1997. Disponível em: $<$ http://willsull.net/la370/resources/Ecology/Daily.pdf>. Acesso em: 04/11/2015

FIOCRUZ. 2014.Ecossistemas: A vida se espalha. Disponível em: $<$ http://www.invivo.fiocruz.br/cgi/cgilua.exe/sys/start.htm?infoid=1364\&sid=2>. Acesso em: 06/10/2015.

GOOGLE EARTH PRO. Disponível em: $<$ https://www.google.com.br/earth/download/thanks.html\#os=win\#version=pro\#usages tats=yes\#updater=yes $>$. Acesso em: 20/09/2015.

INSTITUTO BRASILEIRO DO MEIO AMBIENTE E DOS RECURSOS NATURAIS RENOVÁVEIS-IBAMA,2015. Disponível em: $<$ http://www.ibama.gov.br/rama/metodologia-pressao-estado-impacto-resposta-peir>. Acesso em: 06/10/2015.

INSTITUTO BRASILEIRO DE GEOGRAFIA E ESTATÍSTICA - IBGE. 2015. Gráficos populacional de crescimento econômico e imagem da região de Caravelas. Disponível em: <http://cidades.ibge.gov.br/xtras/perfil.php?codmun=290690>. Acesso em:28/09/2015.

INSTITUTO BRASILEIRO DE GEOGRAFIA E ESTATÍSTICA - IBGE. 2015. Gráficos populacional, de crescimento econômico e imagem da região de Mucuri. Disponível em:

$<$ http://cidades.ibge.gov.br/xtras/perfil.php?lang=\&codmun=292200\&search=bahia|mu 
curi>. Acesso em:28/09/2015.

JAWORSKI,S.K. Caracterização espaço-temporal do sistema estuarino-lagunar de Cananéia-Iguape (SP) a partir das associações de foraminíferos e tecamebas e suas relações com as variáveis ambientais. São Paulo,2010.p:1-2.Disponível em: $<$ http://www.teses.usp.br/teses/disponiveis/21/21133/tde-04082011163338/en.php.>Acesso em: 25/11/2015.

MINISTÉRIO DO MEIO AMBIENTE - MMA. 2015.A Zona Costeira e seus usos múltiplos: Importância Estratégica e Conflitos Socioambientais. Disponível em: $<$ http://www.mma.gov.br/gestao-territorial/gerenciamento-costeiro/a-zona-costeira-eseus-m\%C3\%BAltiplos-usos >.Acesso em: 23/09/2015.

PEREIRA,D.M. et al. Hidrodinâmica e transporte de material particulado em suspensão sazonal em um estuário dominado por maré: Estuário de Caravelas (BA). 2010.

REVISTA BRASILEIRA DE GEOFÍSICA - RBGf. vol.28 no.3 São Paulo July/Sept. 2010.p:429. Disponível em: <http://www.scielo.br/pdf/rbg/v28n3/08.pdf>. Acesso em :06/10/2015.

SISTEMA DE RECUPERAÇÃO AUTOMÁTICA - SIDRA/IBGE. 2015. Disponível em:<http://www.sidra.ibge.gov.br/> Acesso em: 30/10/2015.

SOUZA,O. S. Geotecnologias aplicadas à análise espaço temporal do uso e da ocupação da terra na planície costeira de caravelas (BA).Boletim Goiano de Geografia $35.1 \quad$ pg:84-85,2015. Disponível em: $<$ http://revistas.ufg.emnuvens.com.br/bgg/article/view/35485>. Acesso em: 30/09/2015.

SUPERINTENDÊNCIA DE ESTUDOS ECONÔMICOS E SOCIAIS DA BAHIA - SEI. 2014. Disponível em:

$<$ http://www.sei.ba.gov.br/index.php?option=com content\&view=article\&id=98\&ltemid $=82>$. Acesso em: 20/09/2015. 